\title{
An examination into the possibility of the UK being a predominantly cannabis producing nation and a methodology of cultivation techniques
}

\begin{abstract}
Previously, the UK has been known to heavily import cannabis from producer countries, more recently vast quantities of cannabis farms are being discovered throughout the nation. This review aims to analyse the evidence supporting that the UK is now a predominantly cannabis producing nation through the use of seizure statistics and farm discovery data, also to explore cultivation techniques utilised by domestic growers. The UK is highly efficient at producing high quality sinsemilla cannabis, with the number of commercial farms being discovered more than doubling between 2007/08-2010/11. The quantity of cannabis plant seizures however, has since fallen from 2011/12-2014/15 which the multiple site model explains. Police budgets are believed to be impacting upon seizure statistics explaining the recent decline in cannabis plants and herbal cannabis seizures. With such large quantities of domestic cannabis being grown, it is surprising that cannabis is still imported. The majority of domestic cannabis growers within the UK accomplish this indoors; facilitated with artificial lighting, soil or hydroponics grow mediums and ventilation systems. Further research is needed to indicate whether the UK has the potential to become an exporter of cannabis.
\end{abstract}

Keywords: cannabis, domestic cultivation, importation, cultivation techniques, grower
Volume 2 Issue 2 - 2016

\author{
Andrew O'Hagan, Amber Parker \\ Department of Science and Technology, Nottingham Trent \\ University, UK
}

Correspondence: Andrew O'Hagan, Department of Science and Technology, Nottingham Trent University, Clifton Lane Nottingham NGI I 8NS, UK, Tel 44II5-8483 I53,

Email andrew.ohagen@ntu.ac.uk

Received: December 18, 2015 | Published: January 28, 2016

\section{Abbreviations}

THC, tetra hydro cannabinol; ACPO, association of chief police officers; HPS, high pressure sodium; UKBA, UK border agency

\section{Introduction}

Cannabis is the world's most widely used illicit drug, with evidence of its use dating back to the Neolithic period, around 4000BC. ${ }^{1}$ The term 'cannabis' is mostly referring to the herb produced from the hemp plant Cannabis sativa, however other preparations such as resin and oil can be made from this flexible plant matter. ${ }^{2}$ The most recognised psychoactive ingredient but not the only one, is $\Delta-9$ tetrahydrocannabinol, THC; it is the main component which causes the characteristic 'high' which many people desire. Cannabidiol is another important component within cannabis; this is non-psychoactive and has potential therapeutic effects such as an anti-inflammatory drug. ${ }^{3}$ Studies into the effects of cannabis have shown that the pharmacological activity of THC is influenced by other components; the main being Cannabidiol. ${ }^{4}$ Both of these compounds are secreted from small secretory glands on the plant called 'trachoma's'. 5

The use of this easily accessible substance is varied from medicinal purposes to social uses. The United Kingdom had previously heavily relied upon imported cannabis resin and herbal cannabis from places such as the Lebanon, the Caribbean and Morocco. ${ }^{1,6}$ The cannabis market at present however could not be more different, with nationwide trends imitating that of a domestically cultivated market (discussed at length in Section 5.5 and 5.6), showing similar parallels to that found in the Netherlands. ${ }^{7}$ With advances in high tech systems, and knowledge of the plant ever broadening, there are now many ways to grow cannabis both indoor and outdoor, small scale or large scale etc. The type of production largely depends upon the motivation behind the grower, discussed further in Section 5.4. Although cannabis is currently a Class B drug under the Misuse of Drugs Act 1971, with a maximum sentence of up to 14 years imprisonment (section 5(5.1)), large numbers of people still knowingly risk the consequences.

An incentive of growing cannabis for some may be the avoidance of criminals, however in some instances they begin supplying to criminals higher up in the chain from who they wanted to avoid in the first instance.$^{8}$ There are many publications and reports relating to: cannabis seizures, domestic cultivation and the prevalence of cannabis farms; however there are discrepancies between them. A reason for this is different publications report on various geographic locations; some take into account the UK as a whole whereas others focus on England and Wales. There are also police forces which do not offer data to these types of studies. The Home Office statistical bulletin provides figures on seizures made by police forces and the UK border agency from the past decade. It is clear from these statistics that herbal cannabis has the highest dominance in UK society over any other illicit drug. 'Weed, Need and Greed' by Potter ${ }^{5}$ gave a comprehensive review of the cannabis market and the domestic cultivation within the UK. Potter ${ }^{5}$ stated that cannabis resin, which once accounted for approximately two thirds of cannabis consumption, has lost a large share in the market as a result of domestic production. This is reinforced by the Association of Chief Police Officers (ACPO) report on cannabis cultivation which highlights the elevated occurrence of commercial cannabis farms throughout the UK.

This indicates that a large amount of herbal cannabis on the market at present is being domestically produced by some of the mere 7,660 
farms identified in 2010/11, ${ }^{6}$ this number has since fallenin 2014/15 Not all academics share the same opinion that domestic cultivation of cannabis is a recent manifestation. Potter ${ }^{5}$ also later went on to describe how it has been around for many years, arriving approximately in the UK by 400AD. This early cultivation of cannabis may not have been for recreational use like at present, but more likely for industrial and/or nutritional purposes. ${ }^{5}$ Exposure by Independent Television gives the basic principles of two types of grower; one who grows for personal use and the other who grows for financial gain. Further research, shows that this can be broken down into further categories:

i. Legal and illegal;

ii. Large scale and small scale; and

iii. Indoor and outdoor cultivation.

Potter $^{5}$ described the presence of legal cultivation of cannabis for medical research in order to provide a full picture of the UK's market. Growing cannabis for scientific purposes is legal; however the correct license has to be held ( $\mathrm{GW}$ pharmaceuticals have this license). Activist and chancer growers are described by Potter $^{5}$ which fall in a different category to personal use or financial gain described by Independent Televisions exposure programme. Thus showing that it is not simple to categorise cannabis growers into two groups and that a more sophisticated model is needed which incorporates all the above. If time had permitted, a study of growers throughout the UK would have been useful, discovering their motivations and methods through observation in order to create a representative model. Indoor cultivation is highly prominent within the UK, with $71 \%$ of cannabis growing respondents of the IDMU 1999 survey growing indoors.

This has been mimicked in more recent years with large scale commercial farms being discovered inside industrial/commercial premises, residential buildings, agricultural premises, sheds and garages. ${ }^{9}$ The initial part of this review will discuss whom, how and where cannabis is cultivated. There are countless different approaches that growers can take ranging significantly depending on variables: the amount of cannabis to be produced; space; technology etc. The latter part and the principal aim of this thesis is to critically analyse the evidence around the statement 'we are now a predominantly cannabis producing nation without reliance on importation'. This will entail evaluating seizure trends of herbal cannabis and cannabis plants by Police forces and the UK border agency. From this, conclusions can be made as to the extent of domestic cultivation within the UK, and whether it is as pronounced as officials say it is. This is a gap within current literature which I intend to answer by the end of this thesis. The scope of this review is limited to focus specifically on the illegally cultivated herbal cannabis, the UK's most seized drug. ${ }^{10}$

However in order to gain an understanding in current trends and a holistic representation of cannabis cultivation, it will be necessary to also analyse the data in cannabis resin. Resin was formerly the most popular form of cannabis, accounting for two thirds of the market however since the take-off of domestic cultivation this has suffered. Statistics from the ACPO on the increased discovery of commercial cannabis farms from 2007 onwards also gives indications as to the extent of domestic cultivation.

\section{Discussion}

\section{i. Self-reported cannabis use}

Cannabis use as a recreational drug is by no means a recent practice; it is the most widely used illicit drug in most English speaking countries; including Canada, New Zealand, the United States and not forgetting the United Kingdom. ${ }^{2}$ By assessing the use of cannabis it will allow an understanding as to why domestic cannabis cultivation is needed to meet such a high demand. According to the Crime Survey for England and Wales, 8.6\% of 16-59 year olds had used illicit drugs between the years $2014 / 15 .{ }^{11}$ Of this cannabis was the most frequently used drug, with $6.7 \%$ of $16-59$ year olds using it within the past year. This percentage has fallen dramatically since records begin in 1996; however it has slightly increased since the previous two years as can be seen by Figure $1 .{ }^{11}$

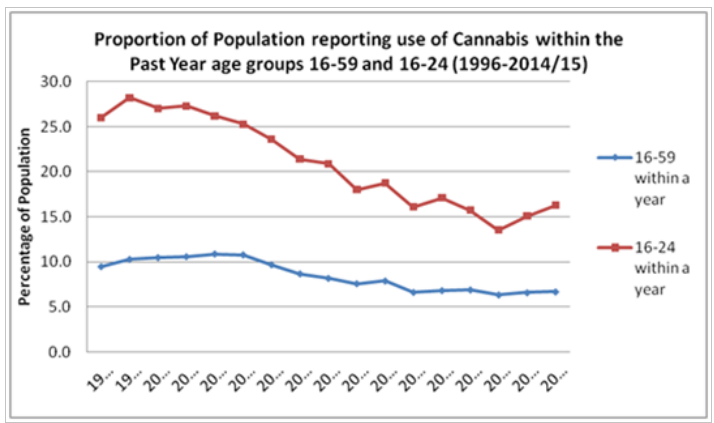

Figure I Self-reported use of Cannabis within the past between 1996 2014/15."

The use of cannabis amongst young adults in the age range of 1624 has significantly fallen since $2002 / 03$, however more recently in the year $2014 / 15$ it has seen a slight incline to $16.3 \%$ compared to the lowest percentage of $13.5 \%$ in $2012 / 13$. This showing that as a general pattern there are less young adults reporting cannabis use compared to when records began in 1996. ${ }^{11}$ (Figure 1), data taken from 'Drugs Misuse: Findings from the 2014 to 2015 Crime Survey for England and Wales' shows the use of cannabis from 1996 until 2014/15. For both age categories, 16-59 and 16-24 year olds, there has been a decline in cannabis use within the past year; however young adults consistently reported a higher percentage use. Possible reasons for this include: young adults being more prone to peer pressure; large amounts of students experimenting; and use as a relaxation remedy. ${ }^{12}$ The statistics received from the Crime Survey show a high degree of reliability. Approximately 50,000 households across England and Wales were invited to take part in the 2012-13 survey, three quarters of these agreed to take part, thus giving a representative sample of the population. $^{13}$

The crime survey incorporates police figures and crimes that may not have been reported to the police in order to give the most accurate statistics on crime data-this is done through the means of the survey, conducted by interview. With the reported use of cannabis apparently in decline amongst the two age groups; the emergence of so many cannabis farms (as will be discussed in section 5.6), whether commercial or otherwise, seems somewhat excessive. Has domestic production now boomed enough to cause a surplus of herbal cannabis within the UK? And if so, where is this surplus going? There could be potential for the UK, an ex-major importer of cannabis to become an exporter. Intelligence provided by the ACPO has indicated that organised crime groups may be supplying skunk amongst other drugs to Europe in order to fill a gap within the market; however there is currently not enough evidence to support the idea of widespread export. ${ }^{6}$ The realms of these questions are beyond the scope of this review; however it provides food for thought of how the market could be changing within the UK. 


\section{ii. The three W's: who, where and why?}

Cannabis cultivation is now a regular phenomenon within the UK, with thousands of cannabis farms being discovered per year. The way in which a cannabis grower administers the grow operation is largely dependent upon their motivation; ${ }^{14}$ thus a wide variety of techniques, methods and yields can be seen across the spectrum. Hough et al., ${ }^{15}$ classifies five types of grower based on the research carried out in the study, these were: the sole use grower; the medical grower; the social grower; the social/commercial grower and finally the commercial grower. This ideology is largely shared by Potter with several additional categories such as co-operatives, franchises and activist growers etc. These types of growers, the location of the grow operation and the techniques which they adopt will be explored thoroughly within this section in order to provide a representative depiction of growers within the UK.

There are three main species of cannabis: Cannabis sativa; Cannabis indica and Cannabis ruderalis. Although sativa is known to be the most common, it is rare to come across this as a pure strain; generally different strains are bred together to form a hybrid with desirable characteristics from each strain such as breeding sativa with indica. ${ }^{16}$ The plant Cannabis sativa, naturally grows in temperate and a tropical region around the world however has now become much more widespread due to the influence of humans. The plant has a lifecycle of around 3-7 months and once germinated can grow rapidly under the correct conditions; with extreme grow rates of up to $15 \mathrm{~cm}$ a day although a more normal rate is of $2-3 \mathrm{~cm}$ per day. ${ }^{5}$ The plant, which is highly adaptable can grow in difficult terrain, however prefers soils high in nitrogen such as loam, ${ }^{17}$ which aids in the flowering of the bud.

Although at present, these strains have been inter-bred multiple times, creating many new strains meaning pure sativa is now rarely seen. ${ }^{16}$ Recent developments have led to plants being grown through the use of hydroponics, growing in water with no soil as a medium ${ }^{15}$ this allows much more control over the nutrients the plant receives. The plant is said to be heliotropic, grows towards direct sunlight, and is a major component which governs the growth of the plant. The first stage of plant development is the growth phase, whereby the plant grows in size and volume. The second stage, when the THC laden resin is produced within trichomes is called the flowering stage; triggered by the amount of daylight and darkness reaching equilibrium, i.e. 12 hours of day, 12 hours of night. This factor can be controlled much easier through the use of grow lights when grown indoors in comparison to traditional methods of outdoor growing. Many cultivators will grow only female plants, the reason for this is the large production of THC in the absence of male plants. When the female plant becomes pollinated, THC production dwindles and energy is concentrated into the production of seeds. ${ }^{5}$

\section{Methods of cannabis cultivation}

The method executed by a potential grower can vary as previously mentioned in Section 5.6 Cannabis cultivation can be very minimalistic and traditional, exerting minimal effort in order to harvest, such as planting a seed in the ground and allowing nature to take its course. This however is not widely adopted across the UK due to issues such as climate, with many growers leaning towards indoor cultivation; this is emphasised by the IDMU Drug Survey which found that $71 \%$ of respondents grew plants indoors compared to $23 \%$ outdoors. The method that the grower pursues will represent several choices which they had to make; the purpose of growing, resources available and security issues. Much of the information within this section relates to Potter ${ }^{5}$ who explored this thoroughly within 'Weed Need and Greed: Domestic Marijuana Production and the UK Cannabis Market'.

\section{Outdoor growing}

Whether to grow outdoor or indoor is a simplistic way to categorise methods of cultivation and is probably one of the first decisions that a potential grower must make. Although many people claim they would like to grow cannabis outdoors, this does not always become reality due to practical reasons, which will be explained later. Outdoor growing can offer numerous advantages to a grower; one of the major reasons is that by using natural methods with sunlight the resulting cannabis is purer and more potent ${ }^{5}$ this is after all the reason to grow cannabis in the first place. However, Potter ${ }^{18}$ states that similar yields and THC concentration can be seen in both indoor and outdoor cultivation. Growing outdoors also gives the plant maximum space for optimum growth whereas indoor growing restricts the growth of the plant due to the limited space available, hence the resulting plants can be of a larger size. ${ }^{5}$ Another factor which is beneficiary and deemed important, is that if the plants were to be discovered it is difficult for law enforcement to link them to an individual and therefore the grower may not face any legal repercussions as a result of detection.

Growing plants outdoors is at a much lower cost when compared to an artificially lit, heated and ventilated indoor grown crop $;^{1}$ allowing more of the profit made from selling the harvest to reach the pocket of the grower, if indeed the harvest is intended to be sold. Finally, some growers have a pure interest in horticulture (the art or practice of garden cultivation and management ${ }^{19,20}$ and want to pursue this interest in a natural way rather than replicating this within an indoor scene. As mentioned, although many people wish to grow outdoors this desire is rarely followed through. Firstly, with many people living in built up urban areas outdoor space is often limited, if present at all, preventing outdoor growing becoming an option. ${ }^{5}$ The lack of private gardens within urban areas is also accompanied by a lack of green spaces in the form of woodlands, parks and fields etc. Another issue which forces people to grow indoors is the matter of losing crop. This can occur through several ways; bad growing conditions, disease, theft and legal actions. Bad growing conditions are inevitable as a consequence of the UK's wet and cold climate; giving the grower little control over the amount of sunlight, water and nutrients that the plant will receive.

Due to the arrival of shorter days later in the season, which is needed to trigger the flowering process, the plants receive a shorter flowering stage and less buds are produced outdoors. ${ }^{21}$ Theft and legal actions only apply once the plant has been discovered by another party, which as stated previously, is difficult to link the plants to the grower. Theft however may be as a result of rivalry and criminal gangs operating within the same geographical area and is seen as a financial loss to the grower in such circumstances. ${ }^{5}$ Factors of crop loss, predominantly only affect those who are cultivating cannabis for financial gain, and are less likely to deter outdoor growing whereby financial gain is not the principal motivation. Potter ${ }^{5}$ identified three main types of outdoor growers: gardeners; farmers and guerrilla growers. Gardeners grow minimal numbers of plants in areas such as their back garden or another safe area of land. The plants are grown for enjoyment and satisfaction, with any successful crop seen as a bonus; the failure of the crop is not much of a worry to these growers as financial gain is not the primary reason for growing in the first place. The gardener will use the harvest for personal use or social supply; 
however the majority of the cannabis consumed is still sourced from the black market. Farmers are described as outdoor growers and aim for a saleable harvest, which would allow profit to be made.

Therefore, more attention is paid to the security, growth and harvest of the plant; this type of grower is not necessarily a 'farmer' in the stereotypical sense. Diversified farmers are those who farm as a legal profession yet turn to cultivating cannabis in order to supplement their farming income. Often rural farmers will choose secluded, hard to access areas to grow their plants, providing a secure location, however maintenance and upkeep proves to be more difficult and the plant is left for long periods of time. Another technique adopted is growing the plants amongst taller crops in the field to offer concealment, thus allowing more regular attendance to the plant, ensuring quality and quantity of harvest. Finally guerrilla growers, defined as growing away from ones property, in public areas or on another's property, ${ }^{22}$ can be broken down further into activists and chancers who practice similar techniques but their motivation differs. Activists want to make a political stance and promote cannabis, by dispersing as many cannabis seeds or plants as they can, scattering handfuls of seeds and making seed balls are two of the methods used. ${ }^{5}$ This can be done anywhere from public parks, roundabouts and gardens yet the activist does not wish to harvest the plant for personal or financial use. Chancers also aim to distribute seeds in a variety of places using similar techniques however their aim is to harvest the plant and more care is taken to ensure the seed/seedling is planted correctly for the increased chance of a successful crop. (Figure 2) below illustrates a location chosen by guerrilla growers to cultivate their plants however

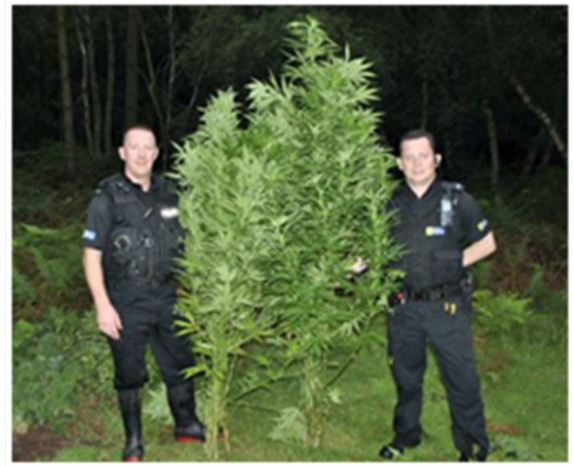

were discovered by Cheshire Police due to a tip-off. ${ }^{23}$

Figure 2 Outdoor guerrilla growing discovered by Cheshire Police. ${ }^{23}$

\section{Indoor growing}

Most commonly, domestically cultivated cannabis is grown indoors within England and Wales according to a study carried out by Hough et al. ${ }^{15}$ The benefits to the grower are numerous; quality and quantity are easily controlled and it provides a secure location in which detection and theft are reduced considerably when compared to outdoor growing. Indoor growing does not necessarily mean a huge factory, where hundreds of plants are being cultivated to be sold commercially, but it also encompasses those who grow a couple of plants in a wardrobe for their own needs. Sometimes, especially in commercial scale grow operations, more than one room is utilised, a separate room for each stage of the cycle $;{ }^{5}$ growth stage and flowering stage. This separation is apparent due to different lighting requirements at each step of the plant cycle. The growth stage as mentioned in section 5.2 is where the plant grows in size, and typically $18-20$ hours of light (artificial light discussed later) is used to encourage maximum growth.

The flowering stage which usually takes place around autumn requires much shorter days, around 12 hours of day and 12 hours of night in order to prompt the production of the resin in the bud. By using multiple rooms, it allows harvest to be staggered giving a continuous supply of cannabis. Some growers will also employ a third room to house seedlings, cuttings and mother plants, Figure $3^{24}$ shows a room dedicated to seedlings. In addition to using multiple rooms to enhance the yield, artificial lighting can be used to manipulate the plants natural growth cycle. In natural conditions, the cycle of a cannabis plant takes a full season and therefore only one harvest can be achieved, ${ }^{5}$ however through the use of high intensity lightbulbs the plant can be tricked into the changing of seasons and adjust the cycle to around 12-14 weeks ${ }^{16}$ giving 3 to 4 harvests per year. A using artificial light allow the plant to produce bigger flowers and consequently more THC than using natural light ${ }^{22}$ and is a possible explanation for the increased use of high power lighting from $17 \%$ to $41 \%$ between the years $1994-2000 . .^{15}$

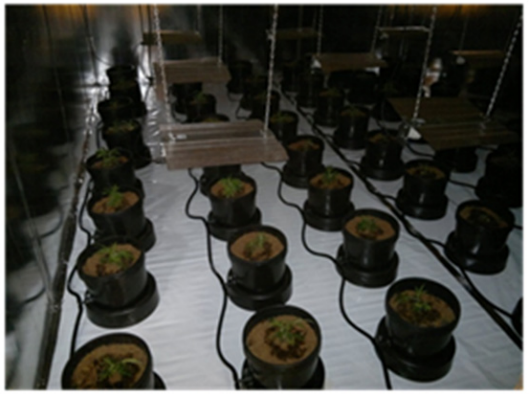

Figure 3 Seedling room discovered in cannabis farm. ${ }^{24}$

Figure 4 shows a set-up within an indoor scene facilitated with artificial lighting. There are many different types of lighting available which are suitable to growing cannabis, the most common being metal halide and high pressure sodium (HPS). ${ }^{15,22}$ HPS lights offer great intensity at the optimum spectrum range, especially within the flowering stage, however can also be used in the growth stage if a metal halide bulb is unavailable, an example of such light bulb is given in (Figure 5). This use of artificial lighting could be a factor which increases the likelihood of detection by law enforcement through the use of thermal imaging cameras used on helicopters, as demonstrated by media headlines such as 'Home cannabis factory found because heat coming from lamps to grow drugs made it look like flat was glowing on police helicopter thermal imaging camera' ${ }^{25}$

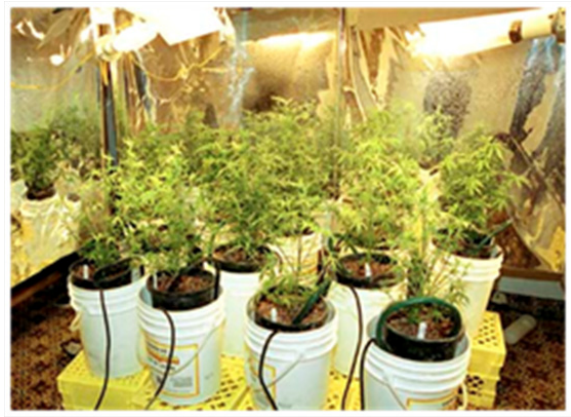

Figure 4 Indoor growing with the use of artificial lighting. ${ }^{16}$ 


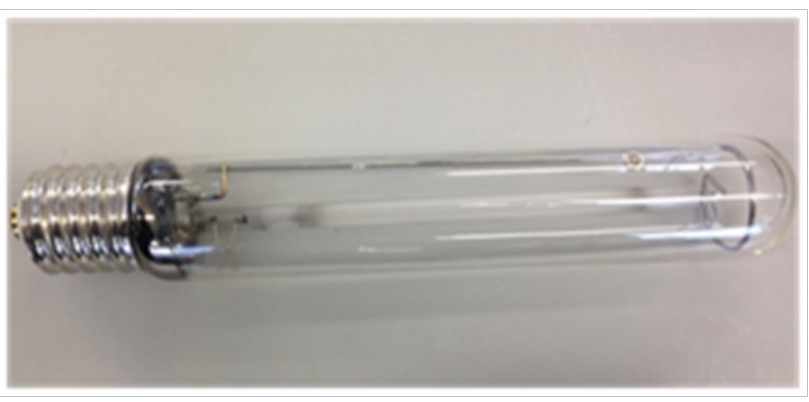

Figure 5 High Pressure Sodium (HPS) light bulb.

Another major distinction between indoor growers is the medium used to grow the plant; soil or hydroponics. Through recent years, the use of more high-tech equipment has become evident; indoor hydroponics more than trebled between the years 1994-2000 from $6 \%$ to $19 \%{ }^{15}$ this however is now somewhat dated and a more recent source, Steve Holme from Derbyshire police explained that at present the majority of discoveries are non-hydroponics. Hydroponic systems allow the plant unrestricted access to any nutrients purposefully added to the water system, unlike soil, meaning lower concentrations are needed in order to fulfil the plants requirements. ${ }^{26}$ The grower also has complete governance over what the plants are fed. ${ }^{5}$ When growing indoors, especially hydroponically, there is a need for further equipment throughout the cycle; many growers opt for ventilation in order to keep conditions dry due to there being a tendency for humidity to accumulate from the high intensity lighting surrounding the water supply. Ventilation also will aid in the removal of unwanted odors associated with growing cannabis. Hot and humid conditions can cause infection amongst the plants in the form of parasites and the growth of algae consuming the nutrient supply. Some growers may also incorporate automated water systems through the use of software packages, allowing the conditions to be thoroughly regulated. There is much more equipment available to growers beyond what has been mentioned in this section which can be purchased from grow shops or online, however the scope of this thesis cannot cover all these aspects but the information is available from other sources.

\section{Greenhouse growing}

Growing cannabis within a greenhouse offers aspects of both indoor and outdoor cultivation, potentially eliminating some of the disadvantageous factors such as high utility costs with indoor growing and the lack of security of outdoor growing. According to Potter $^{5}$ greenhouse growing has declined, with him encountering only very few people who had used them before within his study, however it was much more predominant in the 1980's. Reasons for this may include security issues of having the plant grown in sight of others (such as neighbors) and on their own property. Some potential advantages described by the 420 magazine, ${ }^{27}$ include the ability of the grower to control the conditions such as temperature, humidity and nutrient supply, without the potentially high utility costs that indoor growing would cause. Due to the physical barrier that the greenhouse offers from the outdoors, pests and other unwanted objects such as pollen and competition from surrounding plants often encountered in outdoor growing is omitted, meaning complications are avoided for the greenhouse grower. ${ }^{27}$ Undesirable weather conditions are a common problem experienced by outdoor growers, which could risk the loss of plants and potentially a harvest.
This risk is significantly reduced when grown within a greenhouse due to the shelter it provides from the natural conditions. The greenhouse grower shows an interest in horticulture, with many preferring to grow cannabis organically using traditional methods. High tech equipment which is common when growing indoors (section 5.3.2) is generally not preferential. ${ }^{5}$ In contrast (to Potter), Escondido $^{28}$ describes different methods of greenhouse growing, such as growing in pots or in the ground, with reference to the use of high intensity lighting shown in Figure 6. Using only the natural light provided by the sun, the greenhouse grower can have only one harvest per season. By introducing artificial lighting this can be increased to two or three harvests. This difference between the two authors can be explained by Potter ${ }^{5}$ focusing on only UK growers, whereas Escondido's article available on an American site will not. In certain states within America, cannabis can be used, sold and cultivated legally in certain circumstances, such as for medical reasons..$^{29}$ In some states such as Colorado, possession of cannabis has been decriminalised for everyone.

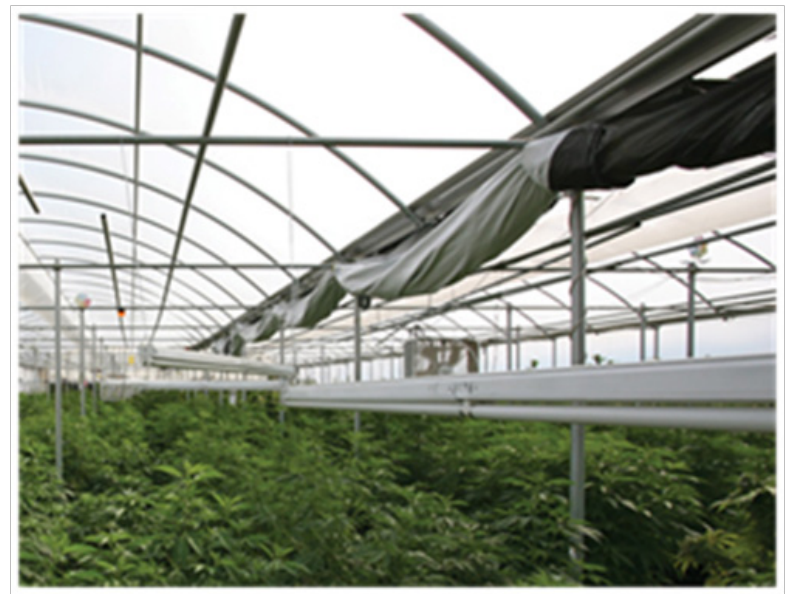

Figure 6 Greenhouse growing with the use of artificial lighting. ${ }^{28}$

\section{Types of cannabis grower}

\section{i. The sole use grower}

Many people use cannabis frequently or on a daily basis, with approximately $15 \%$ of people reporting to smoke cannabis within the past month actually smoking on a daily basis within the UK. ${ }^{30}$ The cost of this to a user can be substantial, with prices averaging at approximately $£ 25$ for an eighth of an ounce of skunk and $£ 20$ for imported herbal cannabis. ${ }^{31}$ Another source, Steve Holme from Derbyshire Constabulary estimated that at present a $£ 10$ deal of cannabis will weigh approximately $0.8 \mathrm{~g}$ and a $£ 20$ deal approximately $1.6 \mathrm{~g}$. These are the two most common weights bought by users. Therefore, it is hardly surprising that some people decide to grow their own cannabis, purely so they don't have to pay street prices. A study carried out in Belgium of small scale cultivators provided evidence that a major motive for the respondents to grow their own cannabis was because it was cheaper, with $79 \%$ rating this as an important factor. ${ }^{32}$ Other motives were to provide for personal use; enjoyment of growing and to experiment.

Interestingly, $90 \%$ of respondents deemed the motive to sell cannabis as not important. Hough et al., ${ }^{15}$ completed a small study into the types of cannabis grower and found that of the 37 growers, 
9 grew explicitly for personal use. By producing their own cannabis, not only does it reduce the cost of being a user but also secures good quality, which is sometimes hit and miss when buying from a dealer. Another benefit which motivates people to begin home growing is that it provides distance between them and the law, no interaction with drug dealers is necessary. ${ }^{15}$ The number of plants that one grows can vary from one or two plants up to two dozen, showing the variability from grower to grower. There is no maximum or minimum number of plants set out in guidelines to what qualifies as a personal use grower; however the more plants that one has, provides the potential for higher yields, which in the eyes of the law could be for the intent to supply.

\section{ii. Social use grower}

Social use growers are those who grow on a non-commercial level for their own personal consumption and that of their friends, ${ }^{15}$ and are a significantly important group, this due to the differentiation between these and commercial growers is somewhat problematic. Both are likely to have in their possession more plants than that of a sole use grower; however the social use grower doesn't have profit as an incentive unlike a commercial grower, although at times the grower may require a small fee from friends in order to cover the growing costs. ${ }^{15}$ This aspect is however hard to prove when the plants have been discovered by the authorities, as much of the same equipment may be in use in both instances. Within Hough et al., ${ }^{15}$ study, they identified 10 out of 37 as social growers with many of them claiming they enjoy the status they acquired for growing good quality cannabis within their social group. This reinforced Weisheit ${ }^{33}$ study conducted in 1991 within the USA, where he identified this as the largest category of grower. It is clear from these two studies alone that social use growers' are not intending to make a profit from their activities, with most giving away cannabis to their friends. The methods employed across social use growers also varies, with some preferring organically grown cannabis in soil to that grown hydroponically, this all depends on factors such as the availability of space, artificial lighting and the amount of time the grower is willing to spend on cultivating their plants ${ }^{5}$ (Figure 7).

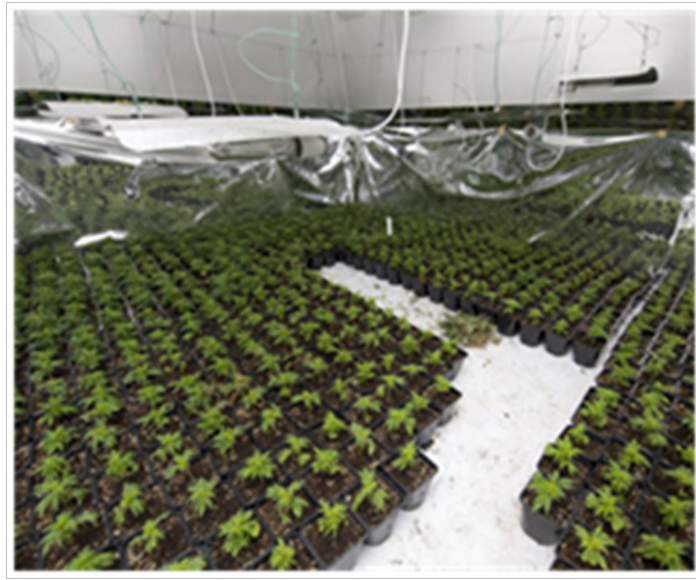

Figure 7 Indoor commercial cannabis farm discovered by Derbyshire Constabulary. ${ }^{16}$

\section{iii. Medical grower}

Although cannabis has not been legally recognised as having therapeutic effects within England and Wales [34], there is nevertheless, a substantial demand for this product amongst people who suffer from pain, multiple sclerosis and depression. ${ }^{35}$ A study carried out by Ware, Adams and Guy involved 2969 participants, all of whom completed a questionnaire regarding the use of cannabis for medicinal purposes. Of the 2969 participants, 947 reported having used it medicinally, with the largest amount of people using 1-2grams per day. This demand for cannabis is recognised by some growers who sell specifically to medicinal users, five medical growers were identified within Hough et al., ${ }^{15}$ study.

Sometimes these types of medicinal users begin cultivating for themselves rather than buying from another source, in the hope to create a cheap and dependable supply of cannabis with little legal implications. Although it is illegal for sufferers to grow their own cannabis or purchase cannabis within England and Wales, the potential benefits of its active ingredients has been acknowledged by GW Pharmaceuticals who have produced a cannabis based product called Sativex. ${ }^{36}$ This company holds one of the only licenses within the UK to grow cannabis legally. Other countries such as Canada have regulations in place such as the Marihuana for Medical Purposes Regulation, to enable Canadians with medical issues to possess and even grow their own cannabis, if the need is supported by a doctor. ${ }^{37}$

\section{iv. Social/commercial grower}

The social/commercial grower is seen as the half-way point between a social and commercial grower as the name suggests, encompassing those who grow for personal use and friends, with the intention to sell their harvest to supplement their income. ${ }^{15}$ The study carried out by Hough et al identified 10 social/commercial growers out of 37 growers in total. The number of plants they grew varied considerably from 2 plants up to 100 plants, depending upon the degree of profit they wish to make. Once again, the technique used by the grower largely depends upon preference and/or circumstances, with half of the growers in the study using organic methods and the other half using hydroponics. ${ }^{13}$ A factor which differentiates these types of growers from the purely commercial category is that they sell only within their social network influence, whereas commercial growers are willing to supply to any individual who presents themselves as a consumer. Similarities can be seen between the social/commercial grower and the pragmatists category described by Weisheit. ${ }^{33}$ Pragmatists are driven to growing cannabis due to economic necessity in a time of hardship, however it is important to acknowledge their motivation is not to gain wealth from the process it is to stabilise their finances, and the size of the grow operation largely depends upon the degree of economic stability which is required by the grower. ${ }^{32}$

\section{v. Commercial grower}

Finally, the category of grower who is most likely to grow the largest quantity of plants is of course the commercial grower as is shown graphically in Figure 8. The motivation behind these people is entirely for profit. Organised criminal gangs are known to have many commercial cannabis factories nationwide, with the number of discoveries more than doubling between $2007 / 08-2010 / 11,{ }^{6}$ possibly due to criminal gangs becoming aware of the huge potential profit to be made in cannabis cultivation, however at present is it thought that the number of discoveries has reached its maximum with figures showing slight decline. ${ }^{16}$ Hough et al. ${ }^{15}$ identified 5 commercial growers within their study in 2003, all of which used a hydroponics system to grow their cannabis. In most cases, commercial growers will have staggered cycles to ensure a plentiful supply is available throughout the year and in order to gain maximum economic profit. 


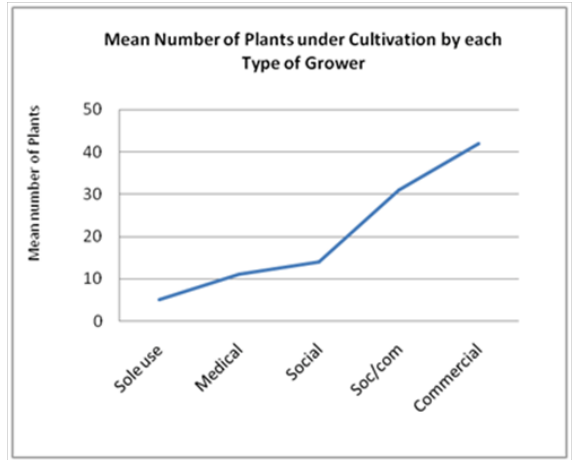

Figure 8 The average number of cannabis plants under cultivation by each type of grower. ${ }^{15}$

An association with organised crime cannabis factories, and the trafficking of individuals into the UK has been ever strengthening, particularly the trafficking of young children from South East Asia such as the Vietnamese.$^{38}$ Children are flown to Russia, and cross over Europe entering the UK mainly through sea ports, from here they are transported to a cannabis factory and forced to work long hours in hazardous conditions. The trafficked children work often as gardeners, tending to the cannabis plants throughout the day and also diverting electricity and breaking into rival cannabis farms. ${ }^{6,38}$ This issue has been highlighted as a consequence of increased commercial factories present within the UK, and needs to be dealt with accordingly to protect the welfare of these children. It is important to note that not all commercial growers are linked to criminal gangs; however the financial gain for some people is too desirable to not pursue.

\section{Cannabis seizures within England and Wales}

Figures on cannabis seizures from 2002-2014/15 are available from the UK Home Office National Statistics, which give an up to date representation of trends in cannabis within England and Wales. (Figure 9) is a summary of this for herbal, resin and plants; this undoubtedly shows the fluctuation of herbal cannabis between the years 2004-2011/12, emphasising this matter further is the appearance of plant seizures increasing year on year until 2011/12.

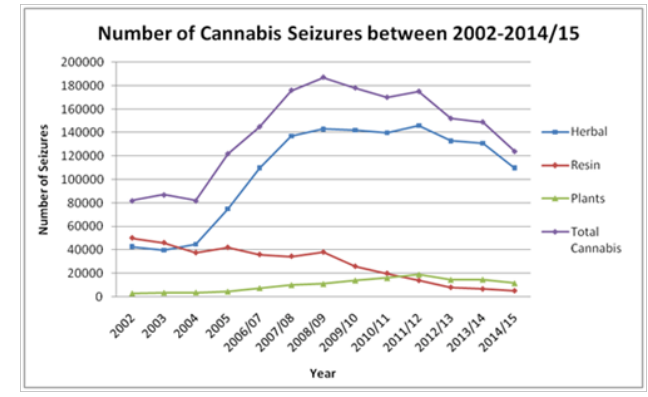

Figure 9 Number of cannabis seizures 2002-2014/15.39

The number of resin seizures can be seen to be making a gradual decline throughout this time span, evidence of a changing market. Within this section, figures regarding the quantity of plants, herbal and resin seizures will be given from 2005 onwards due to the Home Office $^{11,39}$ reporting data from earlier years not being comparable. The series of reports by the Home Office are published yearly, and provide statistics regarding Class $\mathrm{A}, \mathrm{B}$ and $\mathrm{C}$ drugs. The number of seizures made by the police can escalate or decline depending upon the priorities, targets and police powers at that time; such as the introduction of cannabis warnings in $2004 . .^{40,41}$ More recently, police budgets could be the cause of decreased seizures of both herbal cannabis and plants, discussed further in sections 5.5.1 and 5.5.2. Taking into account these factors, caution must be taken as to not mistake the number of drug seizures as the prevalence of drugs in England and Wales. ${ }^{10}$

The Home Office reports on the three main types of cannabis separately; herbal, resin and plants. Thus giving an in-depth breakdown of seizures and also of the different authorities responsible for the seizure; either police or UK Border Agency (UKBA). Herbal cannabis can however be broken down into further categories; the main types available within the UK are sinsemilla and imported marijuana. ${ }^{42}$ Sinsemilla is generally grown indoors under an intense regime and in the absence of male plants to stop fertilisation. ${ }^{1,17}$ The lack of male plants, allows maximum THC production to be achieved ${ }^{5}$ giving sinsemilla the nickname of 'skunk' shown in Figure 10. In comparison, Figure 11 shows imported marijuana from temperate climates which can be grown outdoors and are generally pollinated by male plants. ${ }^{42}$ The Home Office fail to differentiate between these varieties making it difficult to form a conclusion on the prevalence of sinsemilla cannabis, hence domestically produced cannabis in England and Wales Seizures of cannabis plants.

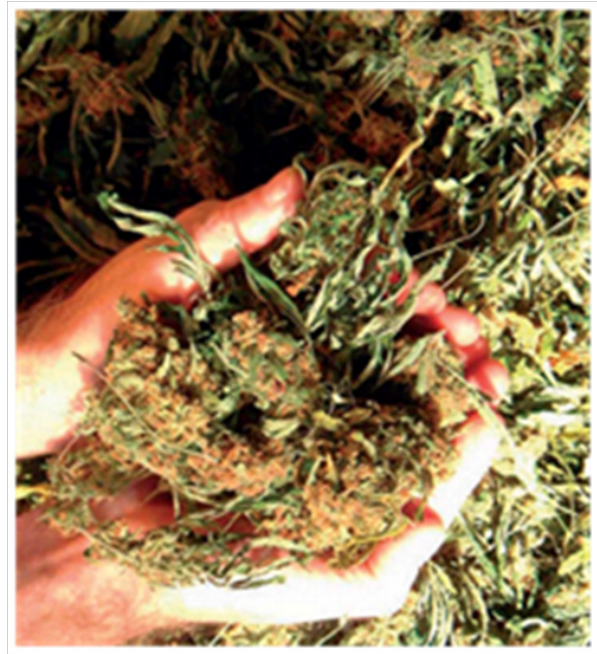

Figure 10 Sinsemilla. ${ }^{62}$

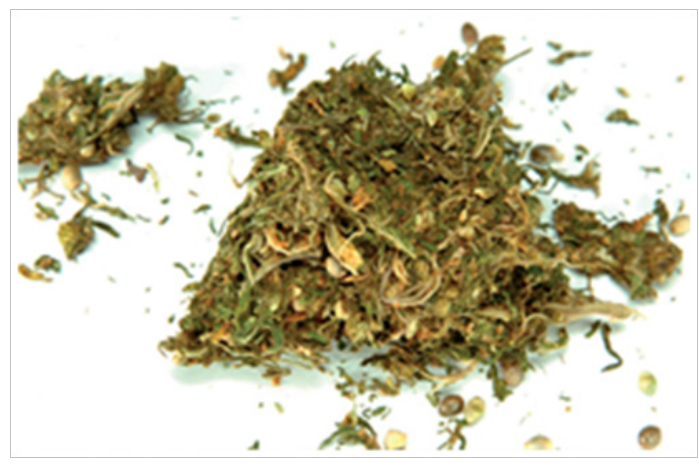

Figure I I Imported Marijuana. ${ }^{62}$ 


\section{Number of cannabis plant seizures}

The number of plant seizures has seen a continuous increase since 2005 until 2011/12. ${ }^{10}$ One reason for this may be the elevated media attention that cannabis had received since the downgrade from a Class B to a Class C drug in 2004, and then back to a Class B drug in $2009 ;{ }^{43}$ this influencing where the police focus their efforts. Heightened concerns with the downgrade in 2004, encouraged police to tackle cultivation in a proactive manner (Figure 12) demonstrates a discovered cannabis farm through police efforts) which may be cause for the increase in seizures year on year. ${ }^{44}$ With this being said, such a dramatic rise must also reflect the possibility that there was a higher proportion of the population willing to grow cannabis, whether this be for personal, commercial or any other use. The uninterrupted rise in cannabis plant seizures ended abruptly in 2012/13, when there was a $10 \%$ fall in seizures; as can be seen in Figure 13 .

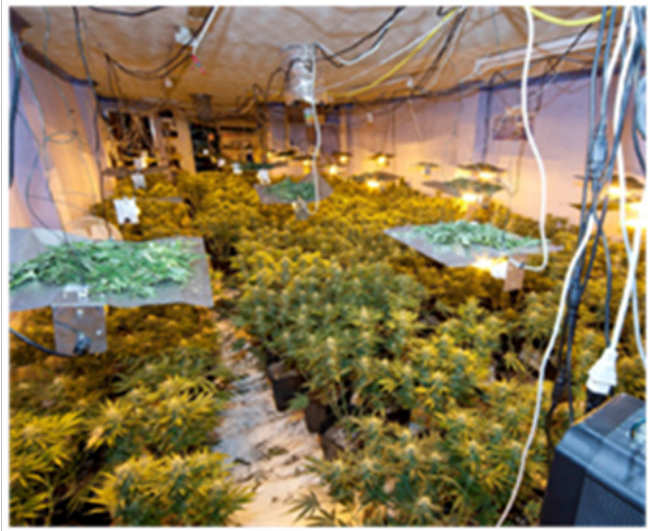

Figure 12 Cannabis farm discovery. ${ }^{6}$

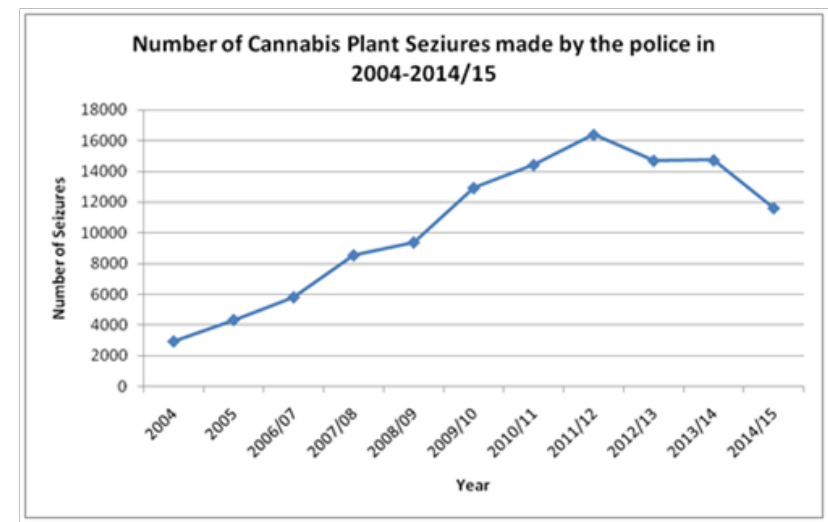

Figure 13 Number of cannabis plant seizures within england and wales, produced using the home office statistical bulletin provided by the home office. $^{10,48-55}$

This decrease continues to $2014 / 15$ where 11,612 seizures were made in comparison to 16,386 in 2011/12. This significant decline in cannabis plant seizures does not mean that there are less cannabis growers or factories, but perhaps a reflection of the police reducing their efforts once again and focussing on harder drugs. ${ }^{6}$ Recent news articles claim that due to police budgets, police forces no longer have the resources to actively seek small scale cannabis farms. ${ }^{45}$ This report would explain the fall in the number of cannabis plant seizures across the UK. Several forces including Durham, Derbyshire and Dorset constabulary have claimed that "austerity cuts to police budgets have forced them to reassess their priorities" and therefore small scale growers are no longer a priority. ${ }^{46}$ The Home Office 2013/14 statistics on drug seizures claim; $90 \%$ of cannabis plant seizures involved 50 plants or less.

Thus if police no longer have the capacity to investigate small cannabis farms, the decline in the number of cannabis plant seizures shown by Figure 14 is not unexpected. The UKBA has not been incorporated into (Figure 13); due to there being no seizures between the years 2004-2011/12 and only one isolated incident in 2012/13, consisting of 5 plants. This is not surprising, as the sale and purchase of cannabis seeds is not and has not been an offence within England and Wales ${ }^{47}$ making the importation of plants an unnecessary occurrence.

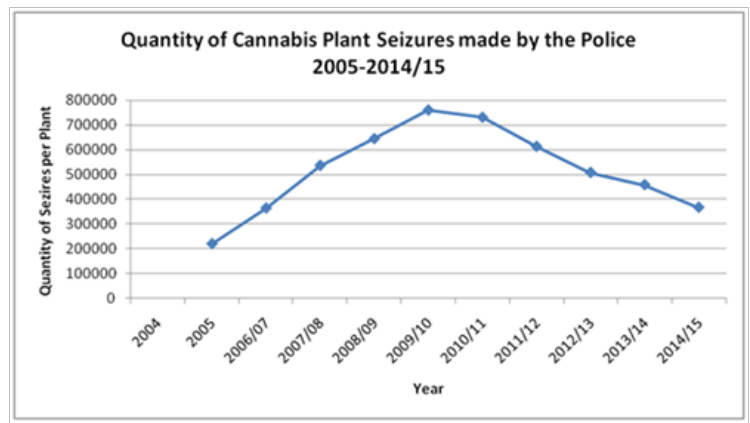

Figure I4 Quantity of cannabis plants seizures, produced using the home office statistical bulletin provided by the home office..$^{10,39,48-56}$

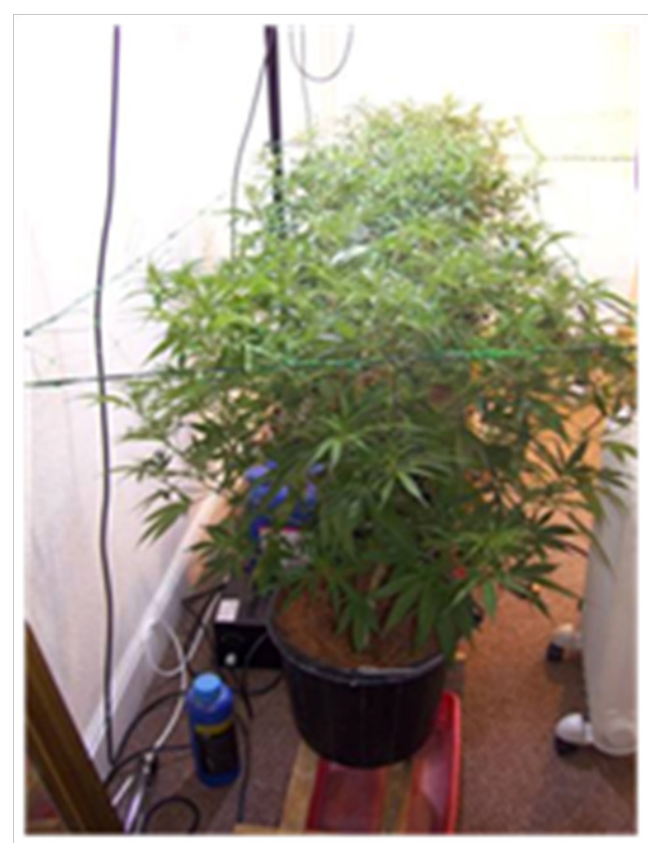

Figure 15 Cannabis plant seized by Derbyshire constabulary..$^{16}$

\section{Quantity of cannabis plant seizures}

Through police efforts and specialised 'cannabis dismantling teams ${ }^{\circ}$ the police have been able to seize 366,841 cannabis plants in the year 2014/15. ${ }^{11,39}$ Although this figure is the lowest since 2009/10 where 758,943 plants were seized; it is still high in comparison to 2004 and earlier. The decline in popularity of cannabis resin ${ }^{5}$ gave the opportunity for the herbal cannabis market, and hence cannabis plants, to dramatically take off. The rapid progression of cannabis plants is represented in Figure 14, which presents the rises and falls 
in the quantity of seizures. The ACPO 'National Problem Profile' on commercial cannabis cultivation 2010 provides an explanation for the abundance of cannabis plants. As more people and criminal gangs recognise the opportunity to make massive financial gain from herbal cannabis, cannabis factories have been relocated from small residential dwellings into large agricultural/industrial premises. These premises have a larger capacity; hence more plants and more money to be made.

If however these factories are discovered, the police will seize a much larger quantity than if in a residential property, thus a contributing factor to the rising presence of cannabis plants up until 2010. The decline in the quantity of plants seized in years 2010-15 can be explained as a combination of austerity among police forces ${ }^{45}$ and commercial growers changing to the 'multiple site' model. ${ }^{6}$ The model explains that smaller scale factories are managed by growers in multiple locations, dispersing the risk of detection and loss of plants if discovered. With this being said, the great boom of cannabis plants that have been seized, particularly between 2004-2009/10, must be evidence of domestic cannabis production rising within England and
Wales. Figure 15 shows a seizure made by Derbyshire Constabulary within a residential dwelling.

\section{Seizures of herbal cannabis}

\section{i. Number of herbal cannabis seizures}

Table 1 below represents data on the number of herbal cannabis seizures from the Police and UK Border Agency from the year 2004 until 2014/2015; ${ }^{10,11,38,48-56}$ The number of herbal cannabis seizures however does not give an accurate insight into the quantity seized (this is discussed in section 5.5.2.2), and assumptions should not be made that more seizures equates to more cannabis. The data shows a sharp increase in the number of seizures by the police for herbal cannabis post 2004 , from 40,682 to 73,671 . This then continues to rise until 2012 with the exception of 2010/11 which saw a slight decline. This dramatic change in number of seizures can be reflected by the introduction of the cannabis warnings in $2004,{ }^{40}$ creating a more time efficient procedure for police officers to seize and record cannabis This is apparent due to warnings being able to be issued away from police stations, unlike the previous procedure of cautioning. ${ }^{10}$

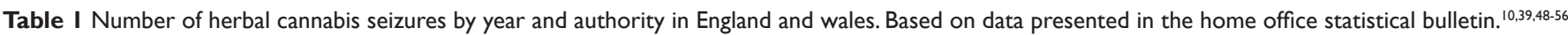

\begin{tabular}{|c|c|c|c|c|c|c|c|c|c|c|c|}
\hline \multirow[t]{2}{*}{ Authority } & \multicolumn{11}{|l|}{ Year } \\
\hline & 2004 & 2005 & $2006 / 07$ & $2007 / 08$ & $2008 / 09$ & $2009 / 10$ & $2010 / 11$ & $2011 / 12$ & $2012 / 13$ & $2013 / 14$ & $2014 / 15$ \\
\hline Police & 40,682 & 73,671 & $\mathrm{I}, 06,208$ & $\mathrm{I}, 34,636$ & $\mathrm{I}, 42,840$ & $1,43,395$ & $1,38,119$ & $1,46,113$ & $|3|, 4||$ & 129,328 & 108,517 \\
\hline UKBA & 2,390 & 2,486 & $3,44 I$ & 2,890 & 2,513 & $|, 06|$ & I, II & $|, 27|$ & 2,030 & I, 929 & 2,109 \\
\hline Total & 43,072 & 76,157 & $1,09,649$ & I,37,526 & $1,45,353$ & $\mathrm{I}, 44,456$ & I,39,237 & $\mathrm{I}, 47,384$ & I,33,44| & 130,045 & 110,626 \\
\hline
\end{tabular}

It also encourages smaller less significant quantities, which in the past offenders may have been given a verbal warning for, to be seized and an appropriate level of punishment given. Figure 16 illustrates the extent of how the introduction of cannabis warnings has skewed data on the number of herbal cannabis possessions. ${ }^{57}$ Pre 2004, the only action available to the police was the act of formally cautioning a person in possession of cannabis.

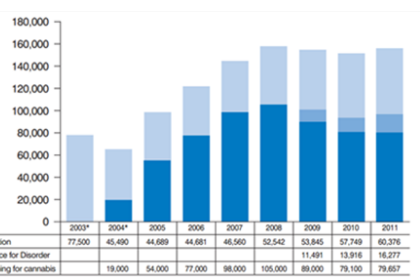

Figure 16 Number of cannabis possession offences by sanction type in England and Wales 2003-2011. ${ }^{57}$

Post 2004, the presence of cannabis warnings is over ruling the way in which cannabis possessions are dealt with, and lead to a heightened number of cannabis seizures. The UKBA, which covers the UK's borders via air and sea, only accounted for a small proportion in the number of herbal cannabis seizures pre 2004; 3,321 and 2,650 in 2002 and 2003 respectively. ${ }^{10}$ These figures have fallen further from 2004 $(2,390)$ to $2012(1,271)$ but slightly increased to $2014 / 15(2,109)$; possibly showing a decreased demand for imported herbal cannabis as a result of domestically cultivated cannabis. Potter et al. ${ }^{42}$ conducted a study into the potency of seized cannabis in 2004/05. The study found that the sinsemilla variety was more common than imported herbal cannabis. This data provides evidence for the type of herbal cannabis which is dominating the market; domestically cultivated cannabis.

\section{ii. Quantity of herbal cannabis seizures}

As mentioned earlier, the quantity of herbal cannabis seized cannot be portrayed by the number of seizures; they must be considered separately. The seizures data available from the Home Office is presented in (Table 2). ${ }^{10,38,48-56,58}$

Table 2 Quantity $(\mathrm{Kg})$ of herbal cannabis seizures by year and authority in England and wales, based on data presented in the home office statistical bulletin. ${ }^{39}$

\begin{tabular}{|c|c|c|c|c|c|c|c|c|c|c|}
\hline \multirow[t]{2}{*}{ Authority } & \multicolumn{10}{|l|}{ Year } \\
\hline & 2005 & $2006 / 07$ & $2007 / 08$ & $2008 / 09$ & $2009 / 10$ & $2010 / 11$ & $2011 / 12$ & $2012 / 13$ & $2013 / 14$ & $2014 / 15$ \\
\hline Police & 3067 & 2884 & 3238 & 4454 & 4967 & 7097 & 4297 & 3796 & 4958 & 4648 \\
\hline UKBA & 17515 & 22948 & 16855 & 28908 & 13254 & 13597 & 17702 & 8488 & 13025 & 10458 \\
\hline Total & 20535 & 25832 & 20093 & 33363 & |795| & 20693 & 22000 & 12284 & 17983 & 15106 \\
\hline
\end{tabular}


The border agency consistently seized a much larger amount of cannabis than the police between the years 2005-2011/12, showing that while they made only 1,271 seizures in the year 2011/12, this accounted for a staggering $17,702 \mathrm{~kg}$ of herbal cannabis. For that reason, the concealments discovered by the UKBA must have contained massive quantities of cannabis. In comparison, the police made 146,113 seizures in 2011/12 which only weighed 4,297kg. More recently in 2014/15, the UKBA continue to seize more than double the quantity than the police $(10,458 \mathrm{~kg}$ compared to a mere $4,648 \mathrm{~kg})$. These figures enforce the opinion that herbal cannabis is still significantly imported into the UK in large quantities, and that the demand for cannabis may potentially not be fully met by domestic production. ${ }^{59}$

From 2005 onwards, the police seized gradually larger quantities of herbal cannabis from 2,940kg in 2004 to $7,097 \mathrm{~kg}$ in 2010/11; as discussed in section 5.5 previously, this could be reflecting a rise in the amount of users converting to herbal cannabis from resin by the means of easily accessible domestically produced cannabis. The series of Home Office publications doesn't differentiate between imported herbal and sinsemilla (domestically produced) cannabis. The Serious Organised Crime Agency (SOCA) do and have estimated between the years 1994-2004 the percentage of police finds that were sinsemilla rose from $11 \%$ to $65 \% .{ }^{6}$ This percentage is predicted to be even higher at present. ${ }^{60}$

\section{iii. Seizures of cannabis resin}

Cannabis resin was once highly popular within England and Wales, with tonnes of it being imported from Morocco (the largest resin producer in North Africa ${ }^{1}$ the Caribbean ${ }^{6}$ and Lebanon. It is one of the many preparations which can be made from the famous Cannabis sativa plant; this however requires much more labour than herbal cannabis to produce and is very rarely seen domestically produced for this reason. ${ }^{15}$ Figure 17 shows the appearance of cannabis resin. ${ }^{61}$

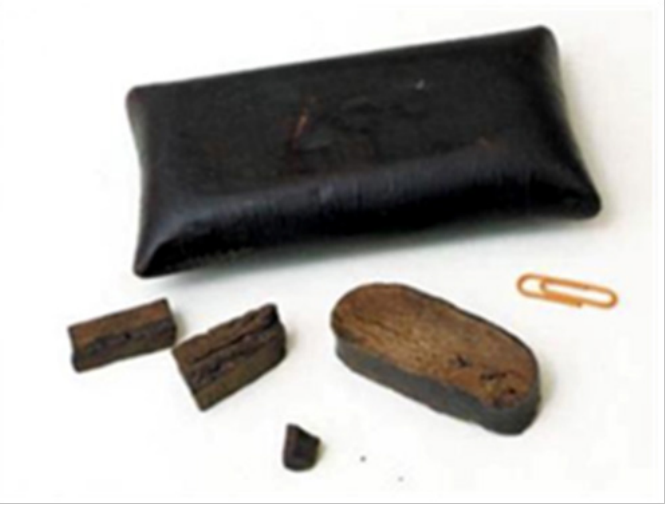

Figure 17 Sample of cannabis resin. ${ }^{61}$

In recent years the popularity of cannabis resin appears to have dropped by a staggering amount and overtaken by herbal cannabis..$^{59}$ This is reflected by the dramatic fall in the number and quantity of resin seizures made by both the police and UKBA. In 2005, there was a recorded 41,454 seizures for cannabis resin this accounting for nearly $50,600 \mathrm{~kg}$; however more recently there were only 14,178 seizures in the year 2011/12 this dropped further to 5,339 in 2014/15. A reason for this apparent shift in the market could be due to the vast amount of domestically cultivated sinsemilla cannabis available from the elevated number of cannabis plants being grown within England and Wales. With such high amounts of herbal cannabis available, there is less demand for resin and hence importation.
This concept is supported by a Home Office study into the potency of cannabis ${ }^{62}$ where 2,914 cannabis samples were submitted by police forces around the country, of these only $15.3 \%$ were resin in contrast to $80.8 \%$ of herbal. Furthermore, $97 \%$ of the herbal cannabis proved to be sinsemilla under microscopic examination; thus giving evidence for domestically cultivated cannabis dominating the market and the need for imported herbal cannabis deteriorating.

\section{iv. The discovery of commercial cannabis farms}

The ACPO has released four UK National Problem Profiles (2010 to 2014) regarding the issue of commercial cannabis cultivation within the UK. The geographical area that this study encompasses includes England, Wales, Scotland and Northern Ireland. Commercial cannabis cultivation has been defined by the ACPO as: Any premises whether commercial or resisdential, shall be deemed a cannabis farm if it has the following: the premises, or part therein, has been adapted to such an extent that normal usage would be inhibited and usually present within the premises, or part therein are items solely concerned for the production of cannabis i.e. hydroponics system. ${ }^{63}$ Between the years of 2004 and 2007, there was an average of 800 cannabis farms discovered per year, this has since escalated to 7,660 in 2010/11. Although the ACPO acknowledge that cannabis importation is still present, the evidence for commercial cannabis cultivation dominating the market is overwhelming.

\section{v. Trends in farm discoveries}

Data relating to the number of cannabis farms that have successfully been discovered by police forces, and the number of plants recovered can give an accurate representation of domestic cannabis production. Table 3 illustrates how the number of discovered cannabis farms has risen since 2007 to $2011 / 12$.

As previously mentioned, the rise in discoveries can be a reflection of police priorities and proactive policing due to public interest in the matter ever growing. Media reports and TV programs have aided in increasing public awareness on the matter, ${ }^{6}$ with headlines such as 'Half a million cannabis growers in UK homes: Criminals are switching over from harder drugs because of more lenient jail sentences' ${ }^{64}$ Communities now have a higher awareness of cannabis within society and reporting levels from neighbors are at the highest. 9 Crime fighting charities such as Crime stoppers are forming campaigns to aid people spot indicatory factors of cannabis production ${ }^{65}$ such as blacked out windows, strange smells and traffic throughout the day and night (whether vehicle or on foot). Nevertheless, the vast amount of discoveries which have occurred cannot be deemed only due to police priorities and public awareness. In the year 2007/08, 3,032 farms were discovered. In comparison, the data from 2010/11 shows an increase of more than $100 \%(7,660)$ farm discoveries.

Data from 2011/12 is portrayed as projected figures, and more recent publications do not clarify these. This projected figure of 7,865 shows stability from the previous year, potentially showing that the number of commercial cannabis farms has reached its peak within the UK. (Table 3) also portrays the number of farms as a percentage of the population; with more and more cannabis farms arising it is hardly a surprise that in 2010/11 there were 13 farms per 100,000 population, more than double that in $2007 / 08$. The abundance of cannabis farms makes it readily available to users across the nation. Many areas have seen large outbreaks of cannabis farms over the years, with South Yorkshire one of the many counties to have witnessed this first hand. In 2007/08 there were 54 farms discovered equating to 5 farms per 100,000 people, jumping ahead to $2010 / 11$ there was a massive 837 
farm discoveries providing 63 farms per 100,000 people. ${ }^{6}$ This pattern can be seen in other counties such as Merseyside, Nottinghamshire and Greater Manchester amongst others. Figure 18 demonstrates the scale of a commercial discovery by Derbyshire Police. Over this 4 year time scale, such a rapid growth in cannabis farm discoveries must be evidence for domestic cultivation rapidly developing and not just enhanced methods of detection by the police. In the most recent ACPO publication on commercial cultivation of cannabis, exact figures are not given to enable a more recent table to be provided.

ACPO 2014 does however state that the number of commercial cultivation offences has decreased by $5.6 \%$ in $2013 / 14$ when compared to $2012 / 13$, this followed a decrease of $3.7 \%$ between $2011 / 12$ and $2012 / 13$. This decline in the number of cannabis farm discoveries does not necessarily mean that cannabis farms are now less frequent, but they are not being actively looked for ${ }^{45}$ Matthew Atha of the Independent Drug Monitoring Unit supported this statement, claiming one of the main detection techniques for cannabis farms was police helicopters fitted with infrared cameras. This resource is highly expensive to run, and police budget cuts have impacted upon their use (Figure 7).

\section{vi. The multiple site model}

Table 3 also represents data on the number of plants discovered within each financial year. As can be seen, between 2007/08 to $2009 / 10$ the number of farm discoveries increased, with this there is a growth in the number of plants recovered. This is not unexpected, as the property of choice at this time is leaning more towards the use of agricultural and industrial/commercial premises; ${ }^{9}$ whereby the floor space is much larger to facilitate a larger scale grow operation. After 2009/10, greater numbers of farms were being discovered supporting the idea of increased domestic production; however the number of plants discovered had fallen. As discussed in section 5.5.1.2 previously, the emergence of the 'multiple site' model would explain these changes. ${ }^{6}$

Table 3 Comparative table of farm discoveries in the UK from 2007/08- 20I I/I2, produced from data provided by the ACPO problem profile.,

\begin{tabular}{lllllll}
\hline & $\mathbf{2 0 0 7 / 0 8}$ & $\mathbf{2 0 0 8 / 0 9}$ & $\mathbf{2 0 0 9 / 1 0}$ & $\mathbf{2 0 1 0 / 1 I I}$ & $\begin{array}{l}\text { Apr-Dec } \\
\text { 20II }\end{array}$ & $\begin{array}{l}\text { 20II/20I2 projected } \\
\text { figures }\end{array}$ \\
\hline $\begin{array}{l}\text { Total number of commercial cannabis } \\
\text { farms }\end{array}$ & 3,032 & 4,951 & 6,866 & 7,660 & 5,899 & 7,865 \\
$\begin{array}{l}\text { Average number of farms per month } \\
\text { Number of farms per 100,000 population }\end{array}$ & 252 & 413 & 572 & 638 & 492 & 656 \\
Number of plants discovered & $5,01,905$ & 8 & 11 & 13 & 9 & 12 \\
\hline
\end{tabular}

Holme, of Derbyshire Police explained that the criminals at the top of the hierarchy became wise to the increased presence of law enforcement which meant cannabis plants were at risk of being seized and a loss of profit for them. However, by dispersing the plants amongst multiple sites the risk was considerably reduced. 2013/14 drug seizure figures from the Home Office reinforce this theory further, as it reports that $90 \%$ of plant seizures involved 50 or less plants evidencing smaller cannabis farms. ACPO further reports that the choice of location for cannabis farms remains domestic dwellings in 2014.

\section{Conclusion}

Between the years 1996-2014/15 the British Crime Survey discovered that the percentage of self-reported cannabis use had declined almost every year, however cannabis was still and is still the UK's most commonly used illicit drug. This substance is particularly popular amongst young adults between 16-24 years old, with $16.3 \%$ reporting use in the past year compared to only $6.7 \%$ of $16-59$ years olds. ${ }^{11}$ The domestic cannabis cultivators within the UK do not all fall into the category of commercial, which the ACPO Problem Profile fails to report on. There are many types of cannabis grower which are sometimes hard to place within a defined category. Hough et al., ${ }^{15}$ provided a basic structure and definition of types of grower: sole use grower; social use grower; medical grower; social/commercial grower and commercial grower. The motivation behind the grower largely dictated the amount of plants which were cultivated, with the sole use grower on average cultivating the least number of plants. Within the UK the location of choice for growing cannabis plants is largely indoors with the addition of artificial light. ${ }^{6,15}$ The security and protection that indoor growing provides is a key consideration when deciding where to start growing cannabis. The potential for higher quality and quantity is also a major initiative for the grower.

Cannabis has been known to grow outdoors within the UK but in much smaller numbers, the unreliability of the weather and the increased risk of detection are some of the factors deterring growers using natural conditions to grow cannabis. Seizure statistics provided by the Home Office in an annual report presented the number and quantity $(\mathrm{Kg})$ of seizures performed by the police and UKBA for cannabis plants, herbal cannabis and cannabis resin. Under observation it was revealed that the number of herbal cannabis seizures had increased unprecedentedly between the years 2004 to 2011/12; meanwhile the number of cannabis resin seizures had been falling, which was once seized at a much higher rate. ${ }^{10}$ Post 2011/12 the number of herbal seizures declined significantly to 108,571 in 2014/15. These figures are somewhat skewed with police priorities and targets affecting them considerably. ${ }^{41}$ The unprecedented incline to $2011 / 12$ can be justified by the introduction of the cannabis warning in $2004,{ }^{40}$ but the most recent decline can be explained by national police budgets. This limited the resources available to proactively discover cannabis farms and prosecute those in possession of cannabis. ${ }^{45}$ Figures also gave evidence that cannabis plants have been more frequently encountered by the police in quantity and number of seizures than in 2004.

From $2006 / 07$ to $2009 / 10$ the quantity of cannabis plants seized more than doubled from 363,679 to 758,943 plants respectively. ${ }^{10}$ This number then fell drastically to 366,841 plants in $2014 / 15$. The dramatic increase in the quantity of plants seized up until 2009/10 supports the belief that we live in a cannabis producing nation, however the recent decline does not prove that we as a nation we are growing less cannabis but probably that it is now not being discovered. The number of seizures made by the UKBA for herbal cannabis has 
dropped; however the quantity $(\mathrm{Kg})$ still remains relatively high allowing the conclusion to be made that herbal cannabis is still imported regardless of the domestic market. The police estimated in 2008 that sinsemilla was now accounting for over $70 \%$ of police finds ${ }^{60}$ showing that domestically cultivated cannabis is dominating the UK market. The dramatic boom in commercial cannabis factories appearing nationwide is not surprising given the potential of the market, with 3,032 commercial farm discoveries in the year 2007/08 which more than doubled to 7,760 in 2010/11. ${ }^{6}$ Although the number of farms has risen in this time frame, the emergence of fewer plants being discovered has become a developing pattern. The ACPO offered an explanation for this which lead them to the multiple site model.

The conversion from using residential dwellings to large scale industrial factories and warehouses accommodated much higher quantities of plants and profit. The risk of these being discovered increased, due to police efforts and potentially equipment advances such as thermal imaging cameras, and it forced the move back to residential buildings; this time in multiple sites. More recently in 2013/14, ACPO stated that the number of commercial cultivation offences had decreased by $5.6 \%$ when compared with the previous year; this followed a decrease of 3.7\% between 2011/12 and 2012/13. These figures may not truly reflect the number of cannabis farms within the UK but be further evidence of police relaxing their efforts on tackling cannabis. This information still provides evidence that the UK is successfully cultivating domestic cannabis with sinsemilla varieties dominating the market over imported cannabis. ${ }^{61}$ This study is a good indication that the United Kingdom are a predominantly cannabis producing nation and advises that further research is needed to assess the impact police austerity is having on seizure statistics but also the potential for the UK to become an exporter of cannabis.

\section{Acknowledgments}

None.

\section{Conflicts of interest}

The author declares that there are no conflicts of interest.

\section{References}

1. EMCDDA (European Monitoring Centre for Drugs and Drug Addiction). EMCDDA Insights: Cannabis Production and Markets in Europe. EMCDDA, UK. 2012a;5-35 p.

2. Shapiro GK, Buckley-Hunter L. What every adolescent needs to know: cannabis causes psychosis. J Psychosom Res. 2010;69(6):533-539.

3. Bisogno T1, Hanus L, De Petrocellis L, et al. Molecular targets for cannabidiol and its synthetic analogues: effect on vanilloid VR1 receptors and on the cellular uptake and enzymatic hydrolysis of anandamide. Br J Pharmacol. 2001;134(4):845-852.

4. Zuardi AW, Crippa JA, Hallak JE, et al. Cannabidiol, a Cannabis sativa constituent, as an antipsychotic drug. Braz J Med Biol Res. 2006;39(4):421-429.

5. Potter G. Weed, need and greed: Domestic marijuana production and the UK cannabis market. University of Sheffield, Department of Law, UK. 2006;228 p.

6. Association of Chief Police Officers (ACPO). UK National Problem Profile: Commercial Cultivation of Cannabis 2012. USA. 2012;1-19 p.

7. Jansen ACM. The economics of cannabis cultivation in Europe. Paris, France. 2002.

8. Exposure: Britain's Booming Cannabis Business (TV) ITV. 2013.
9. Association of Chief Police Officers (ACPO). Findings from the UK National Problem Profile: Commercial Cultivation of Cannabis. UK. 2010 .

10. Kathryn C. Seizures of Drugs in England and Wales, 2011/12, 2nd ed. Home Office, UK. 2012;1-37 p.

11. Deborah L. Drug Misuse: Findings from the 2014/15 Crime Survey for England and Wales, 2nd ed. Home Office, UK. 2015;1-49 p.

12. Child and Youth Health. Cannabis. Australia. 2012.

13. TMS BMRB. About the Crime Survey for England and Wales. Office of National Statistics, UK. 2012;1-26 p.

14. Decorte T, Potter GR, Bouchard M. World Wide Weed. Global trends in cannabis cultivation and its control. Ashgate publishers, Farnham, UK. 2011;314 p.

15. Hough M, Hamish W, Bradley F, et al. A growing market: The domestic cultivation of cannabis. Joseph Rowntree Foundation, UK. 2003;1-60 p.

16. Holme S. Drug Expert: Interview with Amber Parker. Derbyshire, UK. 2014.

17. UNODC. Bulletin on Narcotics: Review of the world cannabis situation. United nations publication, USA. 2006;1-168.

18. Potter D. The increasing potency of street cannabis. 2009.

19. Oxford Dictionaries. Horticulture. 2014b.

20. Oxford Dictionaries. Hydroponics. 2014a.

21. Bone C, Waldron SJ. New trends in illicit cannabis cultivation in the United Kingdom of Great Britain and Northern Ireland. Bulletin on Narcotics. UK. 1999.

22. Green G. The Cannabis Grow Bible: The definitive guide to growing marijuana for recreational and medical use, 2nd ed. Green Candy Press, San Francisco, USA. 2009.

23. Watson L. Guerrilla cannabis growers farm $6 \mathrm{ft}$ tall crop hidden deep in woodland leaving police fearing new tactic in drug production. Mai one. 2012

24. Edwards L. Intelligence Development Officer at South Yorkshire Police: Interview with Amber Parker. Rotherham, UK. 2014.

25. Brady T. Home cannabis factory found because heat coming from lamps to grow drugs made it look like flat was GLOWING on police helicopter thermal imaging camera. 2013.

26. Benton Jones J. Hydroponics: A Practical Guide for the Soilless Grower, 2nd ed. CRC Press. 2005;423 p.

27. What are the Advantages of Growing in a Greenhouse? UK. 420 Magazine. 2007

28. Escondido N. The Luxury of Indoor with the Power of Outdoor. 2012.

29. Cannabis goes on legal sale in US state of Colorado. USA. BBC. 2014.

30. EMCDDA. Prevalence of Daily Cannabis Use in the European Union and Norway. EMCDDA, Lisbon, Portugal. 2012;24 p.

31. IDMU. Cannabis Prices. 2011.

32. Decorte T. Small scale domestic cannabis cultivation: An anonymous Web survey among 659 cannabis cultivators in Belgium. Contemporary Drug Problems. 2010;37(2)341-370.

33. Weisheit RA. The intangible rewards from crime: the case of domestic marijuana cultivation. Crime and Delinquency. 1991;37(4):506-527.

34. Release. The Law on Medical Cannabis in England and Wales. 2014.

35. Ware MA, Adams H, Guy GW. The medicinal use of cannabis in the UK: results of a nationwide survey. Int J Clin Pract. 2005;59(3):291-295. 
36. GW Pharmaceuticals. Sativex. UK. 2014.

37. Health Canada. Information on Law Enforcement. 2013.

38. ECPAT UK. Safeguarding children trafficked to the UK to work in cannabis factories. UK. 2011

39. Jodie H, Kevin S. Seizures of Drugs in England and Wales, 2014/15 Home Office, UK. 2015;1-26 p.

40. Office for National Statistics. Crime in England and Wales, Year Ending June 2013. National Statistics, UK. 2013;1-122 p.

41. Rupert C, John F, Kevin S. Crime in England and Wales 2010/11, 2nd ed. Home Office, UK. 2011;1-110 p.

42. Potter DJ, Clark P, Brown MB. Potency of $\triangle 9-\mathrm{THC}$ and other cannabinoids in cannabis in England in 2005: implications for psychoactivity and pharmacology. J Forensic Sci. 2008;53(1):90-94.

43. Drugscope. Cannabis Laws: Current Classification. 2009.

44. Potter G. The growth of cannabis cultivation: explanations for import substitution in the UK. 2008;1-19 p.

45. $17 \%$ drop in police raids on cannabis farms. Bbc.com. 2015.

46. Police wont target pot smokers and small scale growers, say commissioners. The Guardian. 2015.

47. King LA. The Misuse of Drugs Act: A Guide for Forensic Scientists. Cambridge, The Royal Society of Chemistry, UK. 2003;114 p.

48. Lungowe M, Peter K. Seizures of Drugs in England and Wales, 2004. Home Office, UK. 2006;1-15 p.

49. Home Office. Seizures of Drugs in England and Wales, 2005. UK. 2007.

50. Kevin S. Seizures of Drugs in England and Wales, 2006/07, 2nd ed. Home Office, UK. 2008;1-16 p.

51. Kevin S, Lucy D. Seizures of Drugs in England and Wales, 2007/08. Home Office, UK. 2009;1-18 p.

52. Timothy H, Amartej SR. Seizures of Drugs in England and Wales, 2008/09. Home Office, UK. 2009;1-20 p.
53. Mulchandani Ravi M, Timothy H, Lakhvinder KP. Seizures of Drugs in England and Wales, 2009/10. Home Office, UK. 2010;1-35 p.

54. Kathryn C. Seizures of Drugs in England and Wales, 2010/11, 2nd ed. Home Office, UK. 2011;1-38 p.

55. Kathryn C. Seizures of Drugs in England and Wales, 2012/13. Home Office, UK. 2013;1-17 p.

56. Amardeep D. Seizures of Drugs in England and Wales, 2013/14. Home Office, UK. 2014;1-18 p.

57. Davies C, English L, Stewar C, et al. United Kingdom drug situation: annual report to the European Monitoring Centre for Drugs and Drug Addiction (EMCDDA) 2012. United Kingdom Drug Situation, London, UK. 2012;1-268 p.

58. Home Office. Drug Misuse: Findings from the 2012 to 2013 Crime Survey for England and Wales. UK. 2013.

59. Atha MJ, Davis ST. Taxing the UK Cannabis Market. IDMU Ltd, UK. 2011;1-26 p.

60. Di Forti M, Morgan C, Dazzan P, et al. High Potency Cannabis and the risk of Psychosis. Br J Psychiatry. 2009;195(6):488-491.

61. O'Hagan A. Drugs Awareness Information and Effects. Nottingham Trent University, UK. 2014.

62. Sheila H, Leslie K. Cannabis Potency Study. Home Office, UK 2008;1-20 p.

63. National Police Chiefs' Council (NPCC). UK National Problem Profile: Commercial Cultivation of Cannabis 2014. NPCC, UK. 2014;1-10 p.

64. Doyle J. Half a million cannabis growers in UK homes: Criminals are switching over from harder drugs because of more lenient jail sentences. UK. 2013.

65. Breese C. Neighbours helping police sniff out true scale of cannabis growing in Notts. Soft secrets. 2013. 